\title{
OCORRÊNCIA DE QUEIMA DAS FOLHAS CAUSADA POR Phomopsis sp. EM AROEIRA NO DISTRITO FEDERAL*
}

\author{
JOSÉ R. N. ANJOS, MARIA J. A. CHARCHAR \& DANIEL P. GUIMARÃES \\ Centro de Pesquisa Agropecuária dos Cerrados, Empresa Brasileira de Pesquisa Agropecuária, Cx. Postal 08223 \\ CEP 73301-970, Planaltina-DF
}

(Aceito para publicação em 18/04/2001)

Autor para correspondência: José Ribamar N. dos Anjos

ANJOS, J.R.N., CHARCHAR, M.J. A. \& GUIMARÃES, D.P. Ocorrência de queima das folhas causada por Phomopsis sp. em aroeira no Distrito Federal. Fitopatologia Brasileira 26:649-650. 2001.

\section{RESUMO}

O fungo Phomopsis sp. foi consistentemente isolado de plantas de aroeira (Myracrodruon urundeuva.) com sintomas de queima nas folhas, no Distrito Federal, em 1999. Testes de patogenicidade em casa de vegetação confirmaram Phomopsis sp. como o agente etiológico da doença. Dezesseis, de 20 outras espécies vegetais inoculadas em condições similares, também foram suscetíveis ao fungo. fungos.

\section{ABSTRACT \\ Occurrence of leaf blight caused by Phomopsis sp. on aroeira in Federal District, Brazil}

The fungus Phomopsis sp. was consistently isolated from blighted leaves of aroeira trees (Myracrodruon urundeuva) in Federal District, Brazil, in 1999. Pathogenicity tests on aroeira seedlings under greenhouse conditions have confirmed the fungus as the causal organism of the disease.
Symptoms of leaf blight appeared six to eight days after inoculation. The $\alpha$ conidia of the pathogen were 5,3-7,8 x 2,0-2,7 $\mu \mathrm{m}$, hyaline, ellipsoid to ovoid, and the $\beta$ conidia were $17,5-.27,5 \times 0,5 \mu \mathrm{m}$, filiform, mostly curved and hyaline.
A aroeira (Myracrodruon urundeuva Fr. All.), espécie florestal da família Anacardiaceae, ocorre desde o Ceará até a Argentina e Paraguai, indo das formações mais secas e abertas até às mais úmidas e fechadas (Rizzini, C.T., 1971, citado por Moraes et al., 1992; Lorenzi, 1998). Suas cascas, raízes, folhas e frutos têm amplo uso popular medicinal, além de outros (Almeida et al., 1998). Sua madeira densa $(1,19 \mathrm{~g} /$ $\mathrm{cm}^{3}$ ) e de grande resistência mecânica e durabilidade presta -se para muitas atividades na área de construções rurais, móveis e objetos de adorno (Melo, 1991).

O objetivo dessa comunicação foi relatar uma doença foliar em aroeira, caracterizada sintomatologicamente como queima de limbos, em 1999, na Fundação Zoobotânica do Distrito Federal, Gama, DF. Os sintomas consistiam de necrose escura predominantemente nos bordos dos folíolos (Figura 1-A). No isolamento de fungos em BDA, a partir de folhas com lesões, constatou-se somente colônias de Phomopsis sp. Culturas monospóricas desse fungo foram remetidas para o CABI Bioscience, em Egham, Surrey, Reino Unido, onde foi catalogado como IMI 382250. A identificação do gênero foi confirmada pelo Dr. P.F. Cannon, sem contudo,

\footnotetext{
*Apoio financeiro: Fundação de Apoio à Pesquisa do Distrito Federal (FAP$\mathrm{DF})$.
}

ter sido possível identificar a espécie.

Os conídios do fungo eram de dois tipos: $\alpha$ - medindo 5,3-7,8 x 2,0-2,7 $\mu \mathrm{m}$, hialinos, predominantemente elipsóides para ovóides, gutulados, normalmente com uma gota em cada extremidade, sem sptos; $\beta$ - medindo 17,5-27,5 x 0,5 $\mu \mathrm{m}$, hialinos, sem gotas, filiformes, a maioria curvos em uma das extremidades, ou flexuosos, sem septos.

Para confirmar a patogenicidade desse fungo, procederam-se testes de patogenicidade em mudas de aroeira. Cultura monospórica do fungo foi multiplicada em meio V-8 + estreptomicina durante sete dias a $25{ }^{\circ} \mathrm{C}$ em câmara incubadora com $12 \mathrm{~h}$ de luz branca. A inoculação foi efetuada em 20 mudas de aroeira, com três meses de idade após a germinação, aderindo-se um disco de cinco $\mathrm{mm}$ de diâmetro da cultura do fungo em V-8 nas folhas, após ferimento com agulha esterilizada. Para manter a umidade após a inoculação, as mudas foram cobertas com sacos plásticos e mantidas em bandejas com água dentro de uma câmara de incubação durante $96 \mathrm{~h}$. Vinte mudas sadias, submetidas às mesmas condições, exceto que o disco de V-8 não continha fungo, serviram como testemunhas. Em seguida, as mudas foram transferidas para uma casa de vegetação. Os primeiros sintomas de queima (Figura 1-B) apareceram em 18 (90\%) das plantas inoculadas, seis a oito dias após a inoculação, 


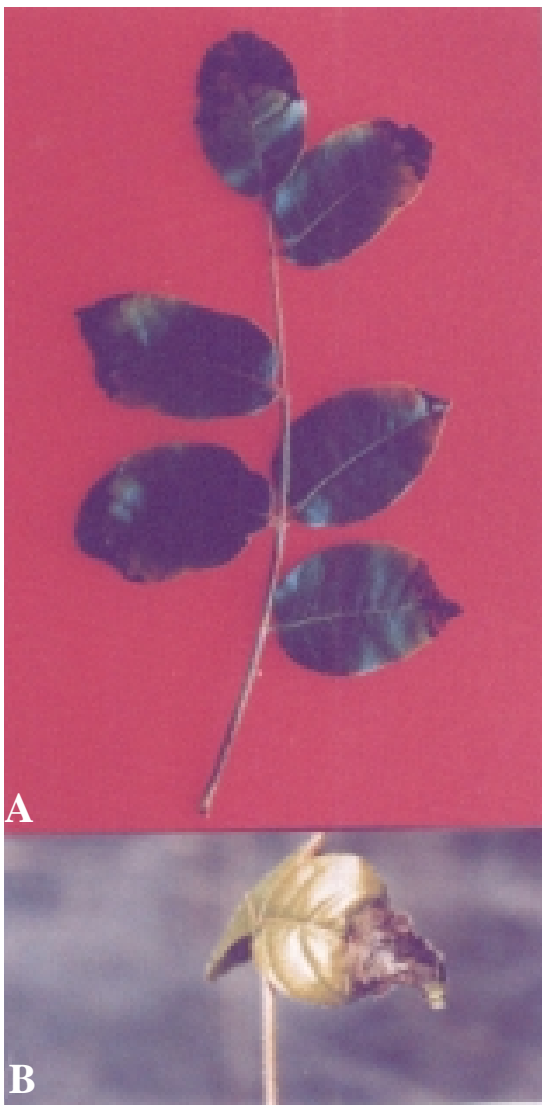

FIG. 1 - Sintomas de queima das folhas em aroeira (Myracrodruon urundeuva) induzidos por Phomopsis sp. A) Sintomas em aroeira em condições de campo. B) Queima das folhas em aroeira após inoculação com Phomopsis sp.

permanecendo as testemunhas assintomáticas. O reisolamento de Phomopsis sp. comprovou os postulados de Koch, confirmando-se assim, a hipótese de que esse fungo era o agente causal da queima da aroeira.

Utilizando-se do mesmo método de inoculação para aroeira, 20 espécies pertencentes a 13 famílias botânicas foram inoculadas com o isolado de Phomopsis sp. em estudo. Todas as espécies testadas, exceto Inga sp., Joannesia princeps Vell, Gossypium hirsutum L. e Passiflora edulis Sims. f. flavicarpa Deg. mostraram sintomas de queima, semelhantes aos exibidos por $M$. urundeuva (Tabela 1). Esses resultados indicam que aroeira não é hospedeira específica para o isolado de Phomopsis em estudo, podendo portanto, servir de fonte de inóculo para outras espécies vegetais. As inoculações foram repetidas duas vezes, observando-se, em ambas, os mesmos resultados.

TABELA 1 - Reação de espécies vegetais à infecção com o isolado de Phomopsis sp. em estudo

\begin{tabular}{|c|c|c|c|}
\hline Espécie & Família & Nome Comum & P.inoc./P.sint. \\
\hline Anacardium humile Mart. & Anacardiaceae & caju-do-cam po & $10 / 10$ \\
\hline Astronium fraxinifolium $\mathrm{Schott}$. & Anacardiaceae & gonçalo-alves & $10 / 7$ \\
\hline Coffea arabica $\mathrm{L}$. & Rubiaceae & café & $10 / 5$ \\
\hline Caryocar brasiliense $\mathrm{C}$ amb. & Caryocaraceae & piqui & $10 / 8$ \\
\hline Crotalaria junceae & Legum inosae & crotalaria & $15 / 12$ \\
\hline Crotalaria paulinia & Legum inosae & crotalaria & $10 / 6$ \\
\hline Dipteryx alata Vog. & $\begin{array}{c}\text { Leguminosae } \\
\text { (Papilionoideae) }\end{array}$ & baru & $10 / 9$ \\
\hline Eugenia dysenterica M art. ex DC. & M yrtæcea & cagaita & $10 / 6$ \\
\hline Glycine $\max \mathrm{L}$. (Merr.) 'Carla ' & Leguminosae & soja & $20 / 17$ \\
\hline Gossypium hirsutum L. & Malvaceae & algodão & $12 / 0$ \\
\hline Grevillae robusta A. Cunn. & Proteaceae & grevillae & $10 / 7$ \\
\hline Hancornia speciosa $\mathrm{Gomez}$ & Apocynaceae & $m$ angaba & $10 / 6$ \\
\hline Hymenaea stigonocarpa $\mathrm{M}$ art. & Legum inosae & jatobá & $10 / 5$ \\
\hline Inga sp. & Mimosaceae & ingá & $10 / 0$ \\
\hline Joannesia princeps Vell. & Euphorbiaceae & cutiera & $10 / 0$ \\
\hline Lycopersicon esculentum Mill. & Solanaceae & tomate & $10 / 6$ \\
\hline Mangiferae indica L.' T. A tkins' & Anacardiaceae & manga & $10 / 6$ \\
\hline Passiflora edulis \$.ims. F.Flavicarpa Deg. & Passifloraceae & m aracujá-azedo & $10 / 0$ \\
\hline Phaseolus vulgaris L.'Pérola' & Legum inosae & feijão & $20 / 16$ \\
\hline Toona ciliata & Meliaceae & toona & $10 / 6$ \\
\hline
\end{tabular}

${ }^{1}$ P. inoc.- plantas inoculadas; P. sint.- plantas com sintomas.

\section{REFERÊNCIAS BIBLIOGRÁFICAS}

ALMEIDA, S.P., PROENÇA, C.E.B., SANO, S.M. \& RIBEIRO, J.F. Cerrado - espécies vegetais úteis. Planaltina: EMBRAPA-CPAC, 1998.

LORENZI, H. Árvores brasileiras - manual de identificação e cultivo de plantas arbóreas do Brasil. Nova Odessa: Plantarum, 1998.

MELO, J.T. Aroeira: características e aspectos silviculturais. Série Documentos $n^{\circ}$ 38. Planaltina: EMBRAPA-CPAC, 1991.

MORAES, M.L.T., KAGEYAMA, P.Y, SIQUEIRA, A.C.M.F, KANO, N.K. \& CAMBUIM, J. Variação genética em duas populações de aroeira (Astronium urundeuva Fr. All.) Engl.-Anacardiaceae. Revista do Instituto Florestal 4:1241-1245. 1992. 